\title{
Synthesis of Amide-Based Surfactant Inhibitor for Carbon Steel Corrosion Protection Electrochemical Analysis
}

\author{
Xiaoping Wang*, Hanbin Xiao \\ School of Logisitics Engineering, Wuhan University of Technology, 430063, Wuhan, China \\ *E-mail: xiaopingwang zzz@foxmail.com \\ doi: $10.20964 / 2017.01 .14$
}

Received: 6 October 2016 / Accepted: 18 November 2016 / Published: 12 December 2016

In this paper, a variety of amide-based cationic surfactants were synthesized through the chemical route. Then, the properties of the as-prepared surfactants, such as the surface tension, the minimum surface area, the maximum surface excess and the critical micelle concentration, were investigated. The 1H NMR and FTIR spectra was recorded to determine their structures. The corrosion inhibition capacity of the as-synthesized amide-based surfactants was evaluated on the carbon steel, where the polarization, weight loss and electrochemical impedance experiments were performed. It was demonstrated that the surfactants were immobilized well on the surface of the carbon steel, which could be elaborated with Langmuir adsorption isotherm. The influences of various parameters further were investigated and discussed.

Keywords: Amide-based cationic surfactant; Corrosion; Carbon steel; Chemical structure; Surface tension

\section{$\underline{\text { FULL TEXT }}$}

(C) 2017 The Authors. Published by ESG (www.electrochemsci.org). This article is an open access article distributed under the terms and conditions of the Creative Commons Attribution license (http://creativecommons.org/licenses/by/4.0/). 